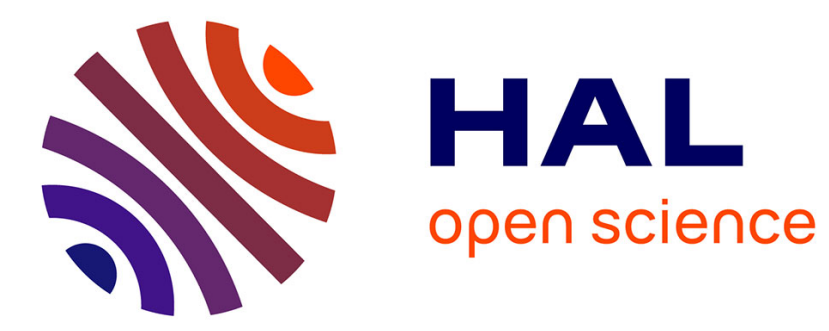

\title{
Adapting the SEPIA system to the educational context
}

Le Vinh Thai, Blandine Ginon, Stéphanie Jean-Daubias, Marie Lefevre

\section{To cite this version:}

Le Vinh Thai, Blandine Ginon, Stéphanie Jean-Daubias, Marie Lefevre. Adapting the SEPIA system to the educational context. EKAW - 19th International Conference on Knowledge Engineering and Knowledge Management, Nov 2014, Linkoping, Sweden. pp.124-128. hal-01301104

\section{HAL Id: hal-01301104 https://hal.science/hal-01301104}

Submitted on 2 Jun 2016

HAL is a multi-disciplinary open access archive for the deposit and dissemination of scientific research documents, whether they are published or not. The documents may come from teaching and research institutions in France or abroad, or from public or private research centers.
L'archive ouverte pluridisciplinaire HAL, est destinée au dépôt et à la diffusion de documents scientifiques de niveau recherche, publiés ou non, émanant des établissements d'enseignement et de recherche français ou étrangers, des laboratoires publics ou privés. 


\title{
Adapting the SEPIA system to the educational context
}

\author{
Le Vinh Thai ${ }^{1,3}$, Blandine Ginon ${ }^{1,2}$, Stéphanie Jean-Daubias ${ }^{1,3}$, and Marie Lefevre ${ }^{1,3}$ \\ ${ }^{1}$ Université de Lyon, CNRS, \\ ${ }^{2}$ INSA-Lyon, LIRIS, UMR5205, F-69621, France \\ ${ }^{3}$ Université Lyon 1, LIRIS, UMR5205, F-69622, France \\ \{name\}. \{surname\} @liris.cnrs.fr
}

\begin{abstract}
The SEPIA system allows creating assistance systems that meet technical assistance needs. In this paper, we aim at the exploitation of SEPIA in the educational context by confronting it to pedagogical assistance needs. This exploitation shows the limitations in the SEPIA system: complex description of rules by pedagogical designers, lack of domain knowledge. Therefore, we present our patterns that facilitate the creation of assistance systems in the educational context and our ideas to allow the exploitation of domain knowledge.
\end{abstract}

Keywords: user assistance, education, pattern, domain knowledge, ILE.

\section{Introduction}

Users often meet difficulties in handling and using applications: they under-exploit those applications by ignoring necessary functionalities and they can even abandon their use. In the educational context, these difficulties, under-exploitation and abandonment, can compromise learning when learners use either ILEs (Interactive Learning Environments), or classical applications for learning. Thus, one solution is the plugging of assistance systems that provide technical assistance to users. This solution can also be used to provide pedagogical assistance, if it is desired by the pedagogical designers or teachers but not supported by the target-applications. We identified the technical and pedagogical assistance needs [2] that an assistance system should meet in an educational context: handling, use, choice of the activity, learning prerequisites, explanation on steps, hints, examples, transitional diagnosis...

Currently several systems (e.g. [1] [3]) allow the specification of assistance systems. However, they are specific to a given environment or to Web applications. By contrast, the SEPIA system [2] proposed in the AGATE project applies an epiphytic and generic approach. It proposes the setup of assistance systems to very diverse existing target-applications and has the capacity to personalize the assistance according to user profile, assistance history, user's past actions and state of the targetapplication. However, the SEPIA system aims only at technical assistance needs because of its generic characteristic. Thus, in this paper, we explain how we adapt it to the specific needs of the educational context.

At first, we present the SEPIA system and its possible exploitation in an educational context by presenting its capacities and identifying its limitations. We then present our solutions to adapt SEPIA to the educational context. 


\section{The SEPIA system}

The AGATE (Approach for Genericity in Assistance To complEx tasks) project aims at proposing generic models and unified tools to make possible the setup of assistance systems in various existing applications, that we call target-applications, by applying a generic and epiphytic approach. This project led to aLDEAS (a Language to Define Epi-Assistance Systems), a graphical rule language allowing assistance designers to define assistance systems and aMEAS (a Model to Execute aLDEAS Assistance Systems) that explains how an assistance system is executed. The SEPIA system (Specification and Execution of Personalized Intelligent Assistance), the first product of AGATE project, is designed and implemented by operationalizing the aLDEAS language and the aMEAS model. The SEPIA system is composed of two main tools: an assistance editor that allows assistance designers to define assistance systems and a generic assistance engine that executes these assistance systems on the target-applications without disturbing them in order to provide assistance to users. The target-applications supported by actual SEPIA are Windows native applications, Java applications and Web applications.

\section{Exploiting SEPIA in the educational context}

SEPIA is designed and implemented by taking into account the technical assistance needs. However, SEPIA can also meet pedagogical assistance needs. In the educational context, the assistance designer is the pedagogical designer who can be a teacher or a group of teachers and the user is mainly a learner. We tested SEPIA in the pedagogical context of a Human-Computer Interaction course. We created an assistance system (as a set of tutorials) for the handling of Java programing in NetBeans IDE. This experiment showed that students can acquire knowledge thanks to our tutorials. Thus, we can conclude from now that SEPIA is also useful in an educational context [2].

However, we identified several limitations to the use of SEPIA to create pedagogical assistances. Firstly, the pedagogical designers may not be familiar with the description of rules because they are not experts of SEPIA. Therefore, they may waste time in technical work instead of concentrating on the pedagogical work. Secondly, in order to propose a more complex assistance, we need domain knowledge that could be described with SEPIA, but complexly. As an example, a learner can submit different good answers if "X-5" is the solution, the system should identify that "X-4-1" or "X-3-2" are correct answers too. The automatic generation of examples or hints also requires domain knowledge in order to have a more suitable assistance.

\section{Adapting SEPIA to educational context}

In this section, we present our solutions to overcome the limitations of exploiting SEPIA in an educational context: proposition of patterns and integration of domain 
knowledge in the system. We aim not only at the technical facilitation of assistance systems description, but also at a more natural description for the designers.

Pedagogical assistances can be examples and explanations that consist of the consecutive steps of assistance or tutorials that merge them (as the tutorials we defined for NetBeans). In order to define such assistance, the designers have to create assistance rules with user consultations. This task is more complex if they want to modify the sequence of steps. Therefore, we proposed and implemented a first pattern called "sequence of steps". Assistance actions are associated with each step. They can be messages, enhancements, links to resources (web pages, programs...) or actions on the interface of the target-application (e.g. a click on a button). We proposed three modes to realize actions on the interface in this first pattern: automating the actions, waiting for user's actions and waiting for user's confirmation of the actions realization. The use of these modes depends on the pedagogical designer's needs and on SEPIA's capacities to detect and automate the actions on the target-application. In addition, we propose in this pattern the possibility to set up the back, next and finish buttons, in order to allow the final user to see again the previous step, the next step or to finish the sequence of steps. The designers can reuse and easily modify the sequence of steps. With this pattern, the pedagogical designers can concentrate less on description of rules and more on their choice of assistance actions for each step. This pattern is implemented and integrated to SEPIA as one assistance action of the system. The figure Fig. 1 shows a screenshot of this pattern that support three modes to realize actions on the interface.

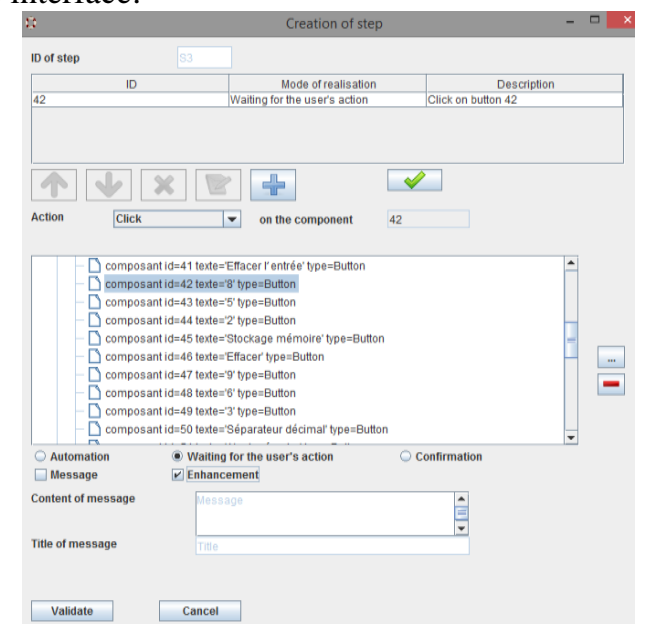

Fig. 1. Screenshot of step creation in the pattern "sequence of steps"

In order to assist more effectively the learner, the designers have to well identify the assistance needs and defining suited assistance rules. The designers first create a set of assistance actions (explanation, examples, hints, etc.) and then have to define conditions to specify how to launch these actions at the right time. We studied the modes of providing assistance in existing educational software: assistance upon the request of the learner, next assistance more detailed or closer to the solution than the 
previous one... These modes are based on different kind of approaches: proactive, reactive, parameterized and mainly mixed. In SEPIA, the application of these modes is compromised by the capacity of SEPIA (technical capacity, lack of domain knowledge) and the difficulty of the rules description (for example, how to provide easily assistance more and more detailed). Thus, we propose a second pattern "assistance needs refinement". We are defining a tree structure of the assistance steps for this pattern that will be then implemented.

More, the recommendation of activities suitable to learner requires organization of the activities. SEPIA does not support this organization. The designers have to create rules, conditions to identify activities suitable to the learner and create learner consultations to know his choice. These tasks are complex and the number of necessary rules is huge. Thus, we plan to implement a third pattern examining researches that concern the recommendation of activities. In addition, we will implement ways of visualizing a summary and a monitoring of activities (e.g. through a progression bar).

Finally, we will focus on defining and implementing an over layer to SEPIA that allows the system to use domain knowledge. We will first have to propose the architecture of this layer. For this purpose, we aim at reusing existing modules that allow pedagogical designers to define different domains knowledge, and at integrating modules of knowledge management specific to a domain (e.g. mathematics).

\section{Conclusion}

We have presented the exploitation of SEPIA in an educational context. SEPIA has been shown to have a strong potential to create assistance systems in an educational context. However, because of the genericity of our approach, it has some limitations. To overcome these limitations, our solutions concern the proposition of patterns and the integration of domain knowledge in our system. Thanks to these solutions, the pedagogical designers will concentrate mainly on the pedagogical works, but not on technical works. In addition, domain knowledge helps them to create assistance systems that provide more appropriate assistance because these systems will know more precisely the learner's problems and the assistance needs. We will validate these solutions by several experimentations with teachers, and students who will play the role of "pedagogical designers". We will compare the use of SEPIA with and without our solutions (patterns and domain knowledge).

\section{Reference}

1. Dufresne, A., Paquette, G.: ExploraGraph: A Flexible and Adaptive Interface to Support Distance Learning. In: Ed-Media, pp 304-309. Victoria, Canada (2000)

2. Ginon, B., Thai, L. V., Jean-Daubias, S., Lefevre, M., Champin, P.-A.: Adding epiphytic assistance systems in learning applications using the SEPIA system. In: Ec-Tel, Graz, Austria (2014).

3. Paquette, G., Pachet, F., Giroux, S., Girard, J.: Epitalk, a generic tool for the development of advisor systems. In: IJAIED, pp 349-370 (1996) 